\title{
ENTROPY-COST RATIO MAXIMIZATION MOdel For EfFicient Stock Portfolio SELECTION USING INTERVAL ANALYSIS
}

\author{
Mainak Dey ${ }^{1}$ and Rupak Bhattacharyya ${ }^{2}$ \\ ${ }^{1}$ Department of Mathematics, Camellia Institute of Engineering, \\ Madhyamgram, West Bengal, INDIA \\ mainak23486@hotmail. com \\ ${ }^{2}$ Department of Applied Science \& Humanities, Global Institute of Management \\ \& Technology, Krishnagar, West Bengal- 741102, INDIA \\ mathsrup@gmail.com
}

\begin{abstract}
This paper introduces a new stock portfolio selection model in non-stochastic environment. Following the principle of maximum entropy, a new entropy-cost ratio function is introduced as the objective function. The uncertain returns, risks and dividends of the securities are considered as interval numbers. Along with the objective function, eight different types of constraints are used in the model to convert it into a pragmatic one. Three different models have been proposed by defining the future financial market optimistically, pessimistically and in the combined form to model the portfolio selection problem. To illustrate the effectiveness and tractability of the proposed models, these are tested on a set of data from Bombay Stock Exchange (BSE). The solution has been done by genetic algorithm.
\end{abstract}

\section{KEYWORDS}

Stock Portfolio Selection, Interval Numbers, Entropy-Cost Ratio model, Dividend, Genetic Algorithm.

\section{INTRODUCTION}

Louis Bachelier's [1] dissertation theory on speculation in 1900 is probably the first attempt to the modern mathematical models of finance. In 1952, Markowitz [2] prominently starts the evolution in modern portfolio selection model analysis and finance management era. Many reasonable works were done since then in this area; the common attempt was maximizing the return or minimizing the risk. Allocation of capital fraction in different risky assets in the most efficient way was always the goal of the researchers.

Many interesting works have been done using different concepts and constraints. Some reasonable works were done using the first two moments of return distributions. Some researchers also have used higher order moments. Arditti [3], Samuelson [4], Kraus and Litzenberger [5], Konno et al. [6], Konno and Suzuki [7], Liu et al. [8], Prakash et al. [9], Lai [10], Chunhachinda et al. [11], Briec et al. [12], Yu et al. [13] are some among those researchers who have invoked these concepts in this area.

Rupak Bhattacharyya et al. (Eds) : ACER 2013, pp. 119-134, 2013. (C) CS \& IT-CSCP 2013

DOI : $10.5121 /$ csit.2013.3212 
However, most of them assumed the security returns as random variables. In 1965, one of the innovative theories of mathematics, Fuzzy set theory, is proposed by Zadeh [14]. Realizing the limitations of stochastic approach to handle such a non-stochastic factor (risky assets), researchers start to involve fuzzy approach to portfolio selection models formulation. Ramaswamy [15], Parra et al. [16], Zhang and Nie [17], Bilbao-Terol et al. [18], Gupta et al. [19], Huang [20, 21], Lin and Liu [22], Bhattacharyya et al. [23, 24, 25], Li et al. [26] and others study fuzzy portfolio selection models.

A special approach, based on interval approximation of fuzzy numbers, assumes that the information of a decision making problem are not well defined but may vary in given intervals. Interval valued fuzzy set theory is introduced separately in the mid-seventies by Grattan-Guinness [27], Jahn [28], Sambuc [29] and Zadeh [30]. Many researchers use interval programming to portfolio selection problem. Parra et al. [16] develop a goal programming (GP) model for portfolio selection, based on the expected intervals of fuzzy numbers that define the objectives and target values. Lai et al. [31] extend the Markowitz's model to an interval programming model by quantifying the expected return and the covariance as intervals. Ida [32, 33], Giove et al. [34], Fang et al. [35], Ehrgott et al. [36], Bhattacharya et al. [37] use interval programming model in various ways. Dividend, transaction cost, liquidity, short and long term return have been used in these models along with mean, variance, skewness.

Maximization entropy principle and minimization cross-entropy principle motivated Kapur and Hesavan [38] to propose an entropy maximization model in 1992. The principle of maximum entropy states that, subject to precisely stated prior data like a proposition that expresses testable information, the probability distribution which best represents the current state of knowledge is the one with largest information-theoretical entropy. The principle was first expounded by E.T. Jaynes in two papers [39, 40] in 1957, where he emphasized a natural correspondence between statistical mechanics and information theory. Later, Fang et al. [41], Qin et al. [42], Li et al. [43], Liu [44] and others also investigate entropy optimization models, which are widely accepted.

The purpose of this paper is to build a new portfolio selection model by making a bridge between these two concepts. Here we have proposed a new objective function as a ratio of entropy to total transaction cost which we want to maximize under the usual constraints on return, risk, dividend etc., but the constraints are treated here in fuzzy interval analytic way. The well known theory of interval numbers and the reason to use it in portfolio models are discussed in the following two sections. In next sections the objective function and constraints are proposed. Then the interval model and an algorithm to solve the problem are discussed. The algorithm is based on the well known Genetic Algorithm; some improvisations have been done to make the algorithm more effective for the particular models. Finally real life market data extracted from Bombay Stock Exchange (BSE) are used to solve the stated models to prove the efficiency of this new approach.

\section{FUZZY INTERVAL ANALYSIS}

Let $R$ be the set of all real numbers. An order pair in a bracket defines an interval

$$
A=[\underline{\alpha}, \bar{\alpha}]=\{x: \underline{\alpha} \leq x \leq \bar{\alpha}, x \in R\},
$$

where $\underline{\alpha}$ is lower bound and $\bar{\alpha}$ is upper bound of interval $A$. The centre and the width of $A$ are defined as,

$$
m(A)=\frac{\bar{\alpha}+\underline{\alpha}}{2} \text { and } w(A)=\frac{\bar{\alpha}-\underline{\alpha}}{2} .
$$


$A$ can also be denoted by its centre and width as

$$
A=\langle m(A), w(A)\rangle=\{x: m(A)-w(A) \leq x \leq m(A)+w(A), x \in R\} .
$$

The annex of ordinary arithmetic to closed intervals is recognized as interval arithmetic. First, we extract some fundamental concepts, as follows:

Definition 1. Let $o \in\{+,-, \times, \div\}$ be a binary operation on $R$. Let $A$ and $B$ be two closed intervals. Then the binary operation on the set of all closed intervals is defined by,

$$
A o B=\{x o y: x \in A, y \in B\}
$$

In the case of division, it is always assumed that $0 \notin B$. The operations on the intervals are as follows:

$$
\begin{gathered}
A+B=[\underline{\alpha}+\underline{\beta}, \bar{\alpha}+\bar{\beta}], \\
A-B=[\underline{\alpha}-\underline{\beta}, \bar{\alpha}-\bar{\beta}], \\
A \pm k=[\underline{\alpha} \pm k, \bar{\alpha} \pm k], k \in R \\
k A=k[\underline{\alpha}, \bar{\alpha}]=\left\{\begin{array}{l}
{[k \underline{\alpha}, k \bar{\alpha}], k \geq 0} \\
{[k \bar{\alpha}, k \underline{\alpha}], k \leq 0}
\end{array}, k \in R\right.
\end{gathered}
$$

An interval number is considered as a special fuzzy number whose membership function takes the value 1 over the interval, and 0 anywhere else. Clearly, the above four operations of the intervals are equivalent to the operations of addition, subtraction and scalar multiplication of fuzzy numbers by means of the extension principle of Zadeh [45]. Rommelfanger et al. [46] inspect the interval programming problem like a fuzzy programming problem. Ishibuchi and Tanaka [47] suggest an order relation among two intervals.

Definition 2. For any two interval numbers $A=[\underline{\alpha}, \bar{\alpha}]$ and $B=[\underline{\beta}, \bar{\beta}]$, there is an interval inequality relation $A \leq B$ among the two interval numbers $A$ and $B$ if and only if, $m(A) \leq m(B)$. .Furthermore, if $\bar{\alpha} \leq \underline{\beta}$, the interval inequality relation $A \leq B$ between $A$ and $B$ is said to be optimistic satisfactory; if $\bar{\alpha} \geq \beta$, the interval inequality relation $A \leq B$ between $A$ and $B$ is said to be pessimistic satisfactory.

\section{USing Interval ANAlysis in Portfolio Modelling}

We know that, in any emerging market, future returns of securities cannot be accurately predicted. Generally, researchers consider the arithmetic mean of historical returns as the expected return of the security. Thus the expected return of the security is a crisp value. Two main problems arise here:

Firstly, if the time horizon of the historical data of a security is very long, the influence of the recent data becomes negligible over that of the historical data.

Secondly, if the historical data of a security is not available in a large scale, one cannot accurately estimate the statistical parameters, due to data scarcity.

Considering these two problems, it is better to consider the expected return of a security as an interval number, rather than a crisp value, based on the arithmetic mean of historical data. Financial reports and the security's historical data can be used to determine the expected return 
interval's range. To determine the range of change in expected returns of securities, the following three factors can be considered:

Arithmetic mean: Arithmetic means of returns of securities should not be expressed as expected returns directly, but can be used as a good approximation. Denote the arithmetic mean return factor as $A\left(r_{i}\right)$, which can be calculated with historical data.

Historical return tendency: If recent returns of a security have been increasing, the expected return of the security is greater than the arithmetic mean based on historical data. However, if recent returns of a security have been declining, the expected return of the security is smaller than the arithmetic mean based on historical data. Denote the historical return tendency factor as $H\left(r_{i}\right)$ , which reflects the tendency of the return on the security. We can use the arithmetic mean of recent returns as $H\left(r_{i}\right)$

Forecast of future returns of a security: The third factor influencing the expected return of a security is its estimated future returns. In a risky modern market scenario the expected return is highly influenced by the present financial condition of a particular corporation which may be highly anomalous. Denote the forecast return factor as $F\left(r_{i}\right)$. Computation of derivation of $F\left(r_{i}\right)$ requires some forecasts based on the financial reports and individual experiences of experts of the market.

Based on the above three factors, we can derive lower and upper limits of the expected return of the security. We can put the minimum of the three factors $A\left(r_{i}\right), H\left(r_{i}\right)$ and $F\left(r_{i}\right)$ as the lower limit of the expected return, while we can put the maximum value of the three factors as the upper limit of the expected return of the security.

Similarly, in fuzzy environment the risk and dividend are also unpredictable. So the variances, covariance and dividends are also considered here as fuzzy interval numbers.

\section{The PORTfolio SELECTION MODEL}

Here we first describe the assumptions and notations used in this paper. Then in the subsequent subsections the objective function and the constraints have been constructed. The fourth subsection presents three different mathematical models for different situations. Finally the optimization algorithm, which is used here to solve the models, has been discussed.

\subsection{Assumptions and notations}

Let us consider a financial market with $n$ risky assets. An investor wants to allocate his wealth among these risky assets. For $i^{\text {th }}$ risky asset $(i=1,2,3, \ldots \ldots \ldots . ., n)$, let us use the following notations:

$x_{i}=$ the proportion of the total capital to be invested,

$d_{i}=$ the estimated annual dividend in the next year,

$r_{i}=$ the expected return,

$\sigma_{i j}=\operatorname{cov}\left(r_{i}, r_{j}\right)$, the covariance between $r_{i}$ and $r_{j}$,

$c_{i}=$ the transaction cost,

$k_{i}=$ the constant cost per change in a proportion, $k_{i} \geq 0$. 


\subsection{Formulation of objective function}

The Principle of Maximum Entropy: Entropy is used to measure the uncertainty associated with each random variable. The Principle of Maximum Entropy is based on the premise that when estimating the probability distribution, you should select that distribution which leaves you the largest remaining uncertainty (i.e., the maximum entropy) consistent with your constraints. That way you have not introduced any additional assumptions or biases into your calculations.

Following the spirit of maximum entropy principle, the total entropy of the allocated proportions of investor's wealth, $E=-\sum_{i=1}^{n} x_{i} \ln x_{i}$ is introduced in the objective function. Kapur [38] introduces it earlier as a single term in that objective function.

Total transaction cost: Let me consider the transaction cost $c_{i}$ to be a V-shaped function of the difference between a given portfolio $x^{0}=\left(x_{1}^{0}, x_{2}^{0}, x_{3}^{0}, \ldots \ldots \ldots \ldots \ldots . . . . ., x_{n}^{0}\right)$ and a new portfolio $x=\left(x_{1}, x_{2}, x_{3}, \ldots \ldots \ldots \ldots \ldots . . . . . ., x_{n}\right) . . H e n c e$, the total transaction cost is,

$$
C=\sum_{i=1}^{n} c_{i}=\sum_{i=1}^{n} k_{i}\left|x_{i}-x_{i}^{0}\right|
$$

which we want to minimize.

Taking these two aspects in consideration, the objective function is formulated as:

$$
\max \frac{-\sum_{i=1}^{n} x_{i} \ln x_{i}}{\sum_{i=1}^{n} k_{i}\left|x_{i}-x_{i}^{0}\right|}=\max \frac{E}{C} \text {. }
$$

\subsection{Construction of the constraints with interval coefficients}

The expected return of portfolio $x=\left(x_{1}, x_{2}, x_{3}, \ldots \ldots \ldots \ldots \ldots, x_{n}\right)$ with transaction cost is given by,

$$
R(x)=\sum_{i=1}^{n} r_{i} x_{i}-\sum_{i=1}^{n} k_{i}\left|x_{i}-x_{i}^{0}\right| \text {. }
$$

Variance of the portfolio is,

$$
\sigma^{2}(x)=\sum_{i=1}^{n} \sum_{j=1}^{n} \sigma_{i j} x_{i} x_{j}
$$

And the estimated annual dividend of the portfolio is,

$$
D(x)=\sum_{i=1}^{n} d_{i} x_{i}
$$

For a new investor it can be assumed that $x_{i}^{0}=0, \forall i=1,2,3, \ldots \ldots ., n$.

From our previous discussion on interval analysis, let $\Delta r_{i l}=r_{i}-\min \left\{A\left(r_{i}\right), H\left(r_{i}\right), F\left(r_{i}\right)\right\}$ and $\Delta r_{i g}=\max \left\{A\left(r_{i}\right), H\left(r_{i}\right), F\left(r_{i}\right)\right\}-r_{i}$.

Then the fuzzy expected return for the $i^{\text {th }}$ security is represented by the interval number: 


$$
\tilde{r}_{i}=\left[r_{i}-\Delta r_{i l}, r_{i}+\Delta r_{i g}\right] \text {. }
$$

Similarly, $\sigma_{i j}$ and $d_{i}$, respectively are represented by:

$$
\tilde{\sigma}_{i j}=\left[\sigma_{i j}-\Delta \sigma_{i j l}, \sigma_{i j}+\Delta \sigma_{i j g}\right], \tilde{d}_{i}=\left[d_{i}-\Delta d_{i l}, d_{i}+\Delta d_{i g}\right]
$$

Then the fuzzy expected return, risk and dividend are respectively defined by,

$$
\begin{gathered}
\tilde{R}(x)=\sum_{i=1}^{n} \tilde{r}_{i} x_{i}-\sum_{i=1}^{n} k_{i}\left|x_{i}-x_{i}^{0}\right|, \\
\tilde{\sigma}^{2}(x)=\sum_{i=1}^{n} \sum_{j=1}^{n} \tilde{\sigma}_{i j} x_{i} x_{j}, \\
\tilde{D}(x)=\sum_{i=1}^{n} \tilde{d}_{i} x_{i} .
\end{gathered}
$$

Since $x_{i} \geq 0$, we have,

$$
\begin{aligned}
& \tilde{R}(x)=\left[R(x)-\Delta_{R l}(x), R(x)+\Delta_{R g}(x)\right], \\
& \tilde{\sigma}^{2}(x)=\left[\sigma^{2}(x)-\Delta_{V l}(x), \sigma^{2}(x)+\Delta_{V g}(x)\right], \\
& \tilde{D}(x)=\left[D(x)-\Delta_{D l}(x), D(x)+\Delta_{D g}(x)\right],
\end{aligned}
$$

where,

$$
\begin{gathered}
R(x)-\Delta_{R l}(x)=\sum_{i=1}^{n}\left(r_{i}-\Delta r_{i l}\right) x_{i}-\sum_{i=1}^{n} k_{i}\left|x_{i}-x_{i}^{0}\right| \\
R(x)+\Delta_{R g}(x)=\sum_{i=1}^{n}\left(r_{i}+\Delta r_{i g}\right) x_{i}-\sum_{i=1}^{n} k_{i}\left|x_{i}-x_{i}^{0}\right| \\
\sigma^{2}(x)-\Delta_{V l}(x)=\sum_{i=1}^{n} \sum_{j=1}^{n}\left(\sigma_{i j}-\Delta \sigma_{i j l}\right) x_{i} x_{j}, \\
\sigma^{2}(x)+\Delta_{V g}(x)=\sum_{i=1}^{n} \sum_{j=1}^{n}\left(\sigma_{i j}+\Delta \sigma_{i j g}\right) x_{i} x_{j} \\
D(x)-\Delta_{D l}(x)=\sum_{i=1}^{n}\left(d_{i}-\Delta d_{i l}\right) x_{i}, \\
D(x)+\Delta_{D g}(x)=\sum_{i=1}^{n}\left(d_{i}+\Delta d_{i g}\right) x_{i} .
\end{gathered}
$$

Now, an investor always prefers a portfolio with having a minimum expected return, a maximum risk tolerance and a higher dividend. So, the following constraints are proposed:

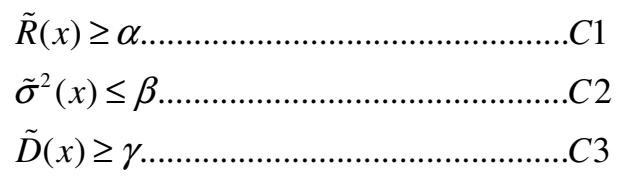

Here $\alpha, \beta, \gamma$ will be allocated by the investor according to the preference.

The well known capital budget constraint on the assets is presented by: 


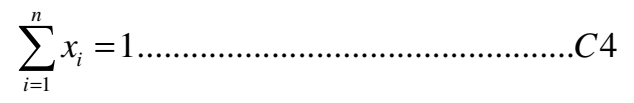

The maximum and minimum fractions of the capital budget being allocated to each of the assets in the portfolio depend upon factors like price relative to the asset in comparison with the average of the price of all the assets in the chosen portfolio, minimal lot size that can be traded in the market, the past performance of the price of the asset, information available about the issuer of the asset, trends in the business of which it is a division etc. Different investors having different views may allocate the same overall capital budget differently.

Let the maximum fraction of the capital that can be invested in a single asset $i$ is $M$. Then

$$
x_{i} \leq M,(\forall i=1,2,3, \ldots \ldots \ldots \ldots, n) \ldots \ldots \ldots \ldots \ldots \ldots . . C 5
$$

Let the minimum fraction of the capital that can be invested in a single asset $i$ is $m$. Then

$$
x_{i} \geq m,(\forall i=1,2,3, \ldots \ldots \ldots \ldots, n) \ldots \ldots \ldots \ldots \ldots \ldots . . C 6
$$

The above two constraints ensure that neither a huge amount nor a very tiny amount of the assets are assigned in a single stock of the portfolio. Huge amount of investment of the asset in a single stock opposes the motto of selecting a portfolio (i.e., diversification of investment). On the other hand, negligible amount of investment in a portfolio is impractical. For example, investing neither $80 \%$ nor $0.5 \%$ of the asset in a single stock of the portfolio is good. Note that for $(n-k)$ number of stocks, we have $x_{i}=0$.

No short selling is considered in the portfolio here. So we have,

$$
x_{i} \geq 0,(\forall i=1,2,3, \ldots \ldots \ldots \ldots, n) \ldots \ldots \ldots \ldots \ldots \ldots \ldots \ldots \ldots
$$

Moreover, it is very difficult for an investor to maintain capital allocations for all available assets in the market, so one can decide to deal with any $k$ no. of assets out of a total of $n$ assets. This leads to the following constraint:

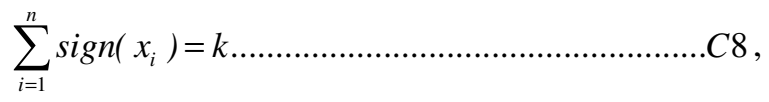

Here $\operatorname{sign}\left(x_{i}\right)$ represents the signum functional value of $x_{i}$.

These are the eight main constraints to be considered in the model discussed in this paper. Obviously, different investors have different approaches towards a problem.

\subsection{Construction of the portfolio selection models}

Using the objective function and the constraints obtained in the previous subsections, the following fuzzy investment problem is constructed: 


$$
\langle 1\rangle\left\{\begin{array}{l}
\max \frac{E}{C} \\
\text { subject to } \\
\tilde{R}(x) \geq \alpha, \tilde{\sigma}^{2}(x) \leq \beta, \tilde{D}(x) \geq \gamma, \sum_{i=1}^{n} \operatorname{sign}\left(x_{i}\right)=k \\
\sum_{i=1}^{n} x_{i}=1, x_{i} \leq M, x_{i} \geq m, x_{i} \geq 0,(\forall i=1,2,3, \ldots \ldots \ldots \ldots \ldots, n) .
\end{array}\right.
$$

Now, denote:

$$
\begin{aligned}
& R_{l}(x)=R(x)-\Delta_{R l}(x), R_{g}(x)=R(x)+\Delta_{R g}(x) \\
& \sigma_{l}^{2}(x)=\sigma^{2}(x)-\Delta_{V l}(x), \sigma_{g}^{2}(x)=\sigma^{2}(x)+\Delta_{V g}(x) \\
& D_{l}(x)=D(x)-\Delta_{D l}(x), D_{g}(x)=D(x)+\Delta_{D g}(x)
\end{aligned}
$$

Then, clearly,

$$
\tilde{R}(x)=\left[R_{l}(x), R_{g}(x)\right], \tilde{\sigma}^{2}(x)=\left[\sigma^{2}{ }_{l}(x), \sigma_{g}^{2}(x)\right], \tilde{D}(x)=\left[D_{l}(x), D_{g}(x)\right] .
$$

From the fuzzy interval optimization model $\langle 1\rangle$, let us construct the following three crisp optimization models $(\langle 2\rangle,\langle 3\rangle,\langle 4\rangle)$, with the help of interval programming by Lai et al. [31].

In the following model $\langle 2\rangle$, the investor estimates the return, risk and dividend pessimistically and aims to optimize the objective based on such constraints.

$$
\langle 2\rangle\left\{\begin{array}{l}
\max \frac{E}{C} \\
\text { subject to } \\
R_{g}(x) \geq \alpha, \sigma^{2}{ }_{l}(x) \leq \beta, D_{g}(x) \geq \gamma, \sum_{i=1}^{n} \operatorname{sign}\left(x_{i}\right)=k \\
\sum_{i=1}^{n} x_{i}=1, x_{i} \leq M, x_{i} \geq m, x_{i} \geq 0,(\forall i=1,2,3, \ldots \ldots \ldots \ldots . ., n) .
\end{array}\right.
$$

In the following model $\langle 3\rangle$, the investor estimates the return, risk and dividend optimistically and aims to optimize the objective based on such constraints.

$$
\langle 3\rangle\left\{\begin{array}{l}
\max \frac{E}{C} \\
\text { subject to } \\
R_{l}(x) \geq \alpha, \sigma_{g}^{2}(x) \leq \beta, D_{l}(x) \geq \gamma, \sum_{i=1}^{n} \operatorname{sign}\left(x_{i}\right)=k \\
\sum_{i=1}^{n} x_{i}=1, x_{i} \leq M, x_{i} \geq m, x_{i} \geq 0,(\forall i=1,2,3, \ldots \ldots \ldots \ldots ., n) .
\end{array}\right.
$$


In following the model $\langle 4\rangle$, the investor chooses a balanced one; to some extent she/he is optimistic, but to some extent she/he is pessimistic too.

$$
\langle 4\rangle\left\{\begin{array}{l}
\max \frac{E}{C} \\
\text { subject to } \\
\lambda_{1} R_{l}(x)+\left(1-\lambda_{1}\right) R_{g}(x) \geq \alpha, \lambda_{2} \sigma_{g}^{2}(x)+\left(1-\lambda_{2}\right) \sigma_{l}^{2}(x) \leq \beta, \\
\lambda_{3} D_{l}(x)+\left(1-\lambda_{3}\right) D_{g}(x) \geq \gamma, \sum_{i=1}^{n} x_{i}=1, \\
x_{i} \leq M, x_{i} \geq m, x_{i} \geq 0,(\forall i=1,2,3, \ldots \ldots \ldots \ldots . . ., n), \\
\sum_{i=1}^{n} \operatorname{sign}\left(x_{i}\right)=k .
\end{array}\right.
$$

Here, $\lambda_{j} \in(0,1)[j=1,2,3]$ would be assigned by the investor.

\subsection{The optimization algorithm}

Genetic algorithm (GA) is a stochastic search method used in computer science field of artificial intelligence and is based on the principles of natural genetic systems. It performs a multidimensional search in providing an optimal solution for evaluation function of an optimization problem mimicking the process of natural evolution. Genetic algorithms belong to the larger class of evolutionary algorithms (EA), which generate solutions to optimization problems using techniques inspired by natural evolution, such as inheritance, mutation, selection, and crossover. Since Holland [48] first proposed it in 1975, genetic algorithm has been widely studied, experimented and applied in many fields like operations research, finance, industrial engineering, VLSI design, pattern recognition, image processing etc.

While solving an optimization problem using genetic algorithm, a population of solutions is evolved towards better solutions. Each population has a set of individuals, its chromosomes or genotypes, which can be mutated and altered. The evolution usually starts from a population of randomly generated individuals and are changed in future generations. In each generation, the fitness of every individual in the population is evaluated, the more fit individuals are stochastically selected from the current population, and each individual's genome is modified using three basic operations on the individuals of the population. The operations are selection, crossing over and mutation. The new population obtained after selection, cross over and mutation is then to generate another population. The new population is then used in the next iteration of the algorithm. Commonly, the algorithm terminates when either a maximum number of generations has been produced, or a satisfactory fitness level has been reached for the population. If the knowledge about the best string is preserved within the population, such a model is called a genetic algorithm with an elitist model (EGA). An EGA converges to the global solution with any choice of initial population (c.f. Bhandari et al. [49]). To find the optimal portfolio, we integrate fuzzy simulation into the GA. The GA procedure has been introduced in detail in Huang [50]. Here, we summarize the algorithm as follows:

1. In the GA, a solution $x=\left(x_{1}, x_{2}, x_{3}, \ldots \ldots \ldots \ldots \ldots, x_{n}\right)$ is represented by the chromosome: 
$C=\left(c_{1}, c_{2}, c_{3}, \ldots \ldots \ldots \ldots, c_{n}\right)$, where the genes $c_{1}, c_{2}, c_{3}, \ldots \ldots \ldots \ldots, c_{n}$ are in the interval $[0,1]$. The matching between the solution and the chromosome is through

$x_{i}=c_{i} /\left(c_{1}+c_{2}+c_{3}+\ldots \ldots \ldots \ldots+c_{n}\right), i=1,2,3, \ldots \ldots \ldots ., n$, which ensures that,

$x_{1}+x_{2}+x_{3}+\ldots \ldots \ldots \ldots+x_{n}=1$ always holds.

Randomly generate a point $C$. Use fuzzy simulation to calculate the values of return, risk and dividend to check the feasibility of the chromosomes. Take the feasible chromosomes as the initial population.

2. Calculate the objective values for all chromosomes by fuzzy simulation. Then, select the best among the chromosomes according to the objective values. The chromosome having the maximum z-value is kept in memory by continuous update. Next, pass the population to perform crossover and mutation.

3. Update the chromosomes by crossover and mutation operations. Check the feasibility of the chromosomes to build a feasible new population.

4. Once again calculate the objective values for all chromosomes by fuzzy simulation. Select the best among the chromosomes according to the objective values. The chromosome having the maximum z-value is kept in memory by continuous update. Next, again pass the population to perform crossover and mutation.

5. Repeat steps 2 to 4 a number of times.

6. The best chromosome obtained at the last iteration is the required solution.

\section{Case Study: Application To Bombay Stock Exchange (BSE)}

Now the portfolio selection model discussed above will be applied to the stock market of Bombay stock exchange (BSE). Bombay Stock Exchange is a stock exchange located on Dalal Street, Mumbai, Maharashtra, India. It is the $10^{\text {th }}$ largest stock exchanges in the world by market capitalization. Established in 1875, BSE Ltd. (formerly known as Bombay Stock Exchange Ltd.), is Asia's first Stock Exchange and one of India's leading exchange groups. Over the past 137 years, BSE has facilitated the growth of the Indian corporate sector by providing it an efficient capital-raising platform. Popularly known as BSE, the bourse was established as "The Native Share \& Stock Brokers' Association" in 1875. Around 5000 companies are listed on BSE making it world's No. 1 exchange in terms of listed members. The companies listed on BSE Ltd command a total market capitalization of USD Trillion 1.2 as of October 31, 2012. BSE Ltd is world's fifth most active exchange in terms of number of transactions handled through its electronic trading system. It is also one of the world's leading exchanges (3rd largest in July 2012) for Index options trading (Source: World Federation of Exchanges).

Here, we have taken 10 companies which are included in BSE index. Their return, dividend and other history has been collected and analyzed carefully for January, 2005 to March, 2010. The data collected is shown in Table 1. The covariance matrix of the return rates of these risky assets are shown in tables 2 and 3 . 
Computer Science \& Information Technology (CS \& IT)

Table 1. Data of Return \& Dividend

\begin{tabular}{|c|c|c|c|c|}
\hline COMPANY & $\begin{array}{c}\text { HIGHEST } \\
\text { RETURN }\end{array}$ & LOWEST RETURN & $\begin{array}{c}\text { HIGHEST } \\
\text { DIVIDEND }\end{array}$ & $\begin{array}{c}\text { LOWEST } \\
\text { DIVIDEND }\end{array}$ \\
\hline TATA POWER & 1.2145 & -0.28425 & 1.20 & 0.85 \\
\hline $\begin{array}{c}\text { RELIANCE } \\
\text { INFRA }\end{array}$ & 1.78775 & -0.484 & 0.70 & 0.11 \\
\hline ITC & 0.49725 & -0.3775 & 3.70 & 2.65 \\
\hline M\&M & 1.135 & -0.3915 & 1.30 & 0.40 \\
\hline GRASIM & 0.9465 & -0.27625 & 3.00 & 1.40 \\
\hline SBI & 0.9775 & -0.25225 & 2.90 & 1.00 \\
\hline WIPRO & 0.78025 & -0.43975 & 2.50 & 0.50 \\
\hline TATA STEEL & 1.3065 & -0.446 & 1.60 & 1.00 \\
\hline ONGC & 0.62975 & -0.3605 & 2.50 & 1.30 \\
\hline TATA MOTORS & 1.3885 & -0.504 & 1.50 & 0.40 \\
\hline
\end{tabular}

Table 2. Lower Covariance Matrix

\begin{tabular}{|c|c|c|c|c|c|c|c|c|c|c|}
\hline$\frac{v}{5}$ & 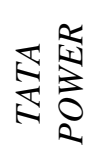 & 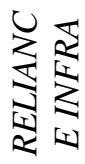 & $\Xi$ & $\underset{z}{z}$ & 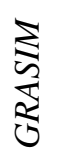 & $\bar{\varpi}$ & $\frac{0}{2}$ & $\begin{array}{l}\mathbb{\pi} \\
\frac{\pi}{\pi} \\
\frac{\pi}{5}\end{array}$ & $\underset{0}{\vdots}$ & 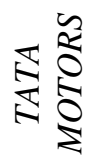 \\
\hline 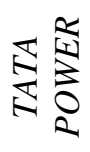 & $\begin{array}{l}n \\
6 \\
\infty \\
\infty \\
0 \\
0\end{array}$ & 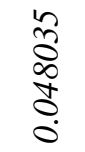 & $\begin{array}{l}0 \\
0 \\
2 \\
\vdots \\
0 \\
0\end{array}$ & 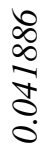 & 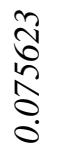 & 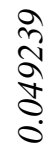 & $\begin{array}{l}m \\
2 \\
\infty \\
8 \\
8 \\
0\end{array}$ & 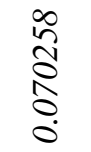 & 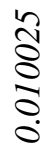 & $\begin{array}{l}n \\
\hat{n} \\
\hat{n} \\
0 \\
0\end{array}$ \\
\hline 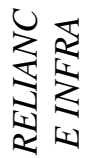 & 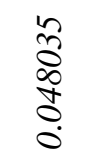 & $\begin{array}{l}\sqrt{\pi} \\
\frac{\sqrt[3]{0}}{0} \\
0\end{array}$ & $\begin{array}{l}\infty \\
\infty \\
\infty \\
\infty \\
0 \\
0\end{array}$ & 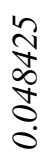 & 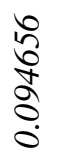 & $\begin{array}{l}\frac{1}{2} \\
\tilde{2} \\
0 \\
0\end{array}$ & 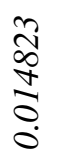 & $\begin{array}{l}2 \\
\hat{n} \\
2 \\
0 \\
0\end{array}$ & $\begin{array}{l}\stackrel{\infty}{n} \\
\underset{\sigma}{\sigma} \\
0\end{array}$ & 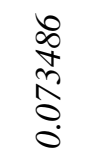 \\
\hline 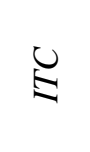 & $\begin{array}{l}a \\
b \\
2 \\
0 \\
0 \\
1\end{array}$ & $\begin{array}{l}\infty \\
\infty \\
\infty \\
0 \\
0 \\
0\end{array}$ & $\begin{array}{l}\frac{\pi}{2} \\
\frac{2}{2} \\
\frac{1}{0}\end{array}$ & \begin{tabular}{l}
\multirow{N}{N}{} \\
$\hat{0}$ \\
0
\end{tabular} & $\begin{array}{l}\hat{b} \\
+ \\
0 \\
0 \\
0 \\
0\end{array}$ & 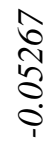 & $\frac{n}{2}$ & $\begin{array}{l}0 \\
2 \\
2 \\
0 \\
0 \\
0\end{array}$ & 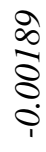 & $\begin{array}{l}\hat{n} \\
\hat{0} \\
0 \\
0\end{array}$ \\
\hline$\underset{z}{\mathbb{Z}}$ & $\begin{array}{l}0 \\
\infty \\
\infty \\
\overline{7} \\
0 \\
0\end{array}$ & 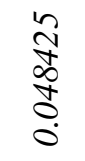 & 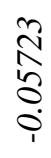 & 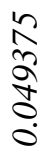 & 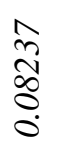 & 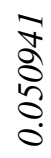 & \begin{tabular}{l}
\multirow{2}{0}{} \\
$\vdots$ \\
0 \\
0 \\
0 \\
0
\end{tabular} & 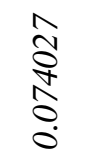 & 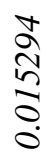 & $\begin{array}{l}\frac{7}{\sigma} \\
\frac{0}{0} \\
0\end{array}$ \\
\hline$\frac{\sqrt[5]{5}}{\frac{5}{5}}$ & 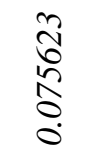 & 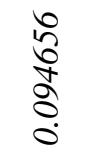 & $\begin{array}{l}\hat{\sigma} \\
+ \\
0 \\
0 \\
0\end{array}$ & 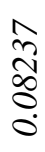 & \begin{tabular}{l}
\multirow{N}{*}{} \\
$\infty$ \\
\multirow{0}{*}{} \\
0
\end{tabular} & $\begin{array}{l}\stackrel{7}{\pi} \\
\frac{0}{0} \\
0\end{array}$ & 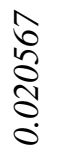 & 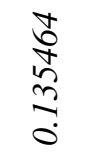 & 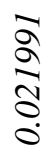 & $\frac{7}{\frac{7}{6}}$ \\
\hline $\bar{\varpi}$ & 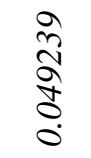 & 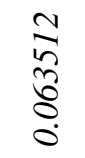 & 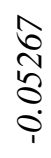 & 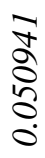 & $\begin{array}{l}\frac{1}{6} \\
\frac{0}{0} \\
0 \\
0\end{array}$ & 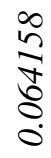 & $\begin{array}{l}\stackrel{n}{N} \\
\stackrel{0}{0} \\
0\end{array}$ & 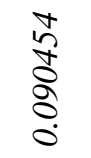 & 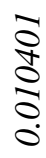 & $\begin{array}{l}0 \\
\infty \\
0 \\
0 \\
0 \\
0\end{array}$ \\
\hline
\end{tabular}




\begin{tabular}{|c|c|c|c|c|c|c|c|c|c|c|}
\hline $\begin{array}{l}0 \\
\vdots \\
\vdots\end{array}$ & $\begin{array}{l}2 \\
\approx \\
\infty \\
\delta \\
\delta \\
0 \\
0\end{array}$ & 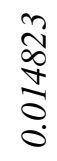 & $\frac{n}{8}$ & \begin{tabular}{l}
\multirow{2}{0}{} \\
8 \\
0 \\
0 \\
0 \\
0
\end{tabular} & 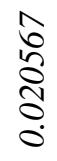 & 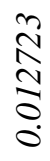 & 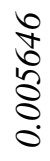 & $\begin{array}{l}\infty \\
\infty \\
\approx \\
0 \\
0\end{array}$ & 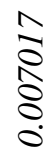 & 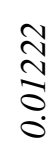 \\
\hline \begin{tabular}{l}
$\mathbb{E}$ 矛 \\
\multirow{5}{*}{}
\end{tabular} & $\begin{array}{l}\stackrel{0}{\mathscr{I}} \\
\stackrel{\Omega}{0} \\
0 \\
0\end{array}$ & $\begin{array}{l}\hat{2} \\
\hat{2} \\
0 \\
0 \\
0\end{array}$ & $\begin{array}{l}\hat{2} \\
\grave{2} \\
\dot{0}\end{array}$ & 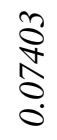 & 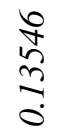 & $\begin{array}{l}\frac{1}{8} \\
8 \\
8 \\
0\end{array}$ & $\begin{array}{l}\infty \\
\stackrel{\infty}{2} \\
0 \\
0\end{array}$ & $\begin{array}{l}\stackrel{\infty}{m} \\
\stackrel{2}{0}\end{array}$ & 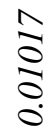 & \\
\hline ๖ & 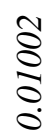 & 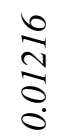 & $\begin{array}{l}\stackrel{2}{8} \\
\stackrel{8}{0}\end{array}$ & 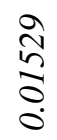 & 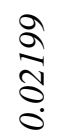 & 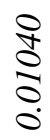 & 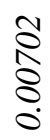 & $\begin{array}{l}\stackrel{ }{\sigma} \\
\stackrel{0}{0} \\
0\end{array}$ & 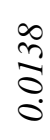 & 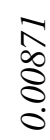 \\
\hline 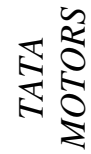 & $\begin{array}{l}n \\
\hat{2} \\
\hat{\sigma} \\
0 \\
0\end{array}$ & \begin{tabular}{l}
$\infty$ \\
\multirow{2}{*}{} \\
$\stackrel{2}{0}$ \\
0
\end{tabular} & $\begin{array}{l}\hat{n} \\
\hat{\sigma} \\
\stackrel{0}{1}\end{array}$ & $\begin{array}{l}\frac{\pi}{6} \\
\frac{0}{0} \\
0\end{array}$ & $\frac{\bar{b}}{\sqrt{7}}$ & $\begin{array}{l}\bar{\infty} \\
\stackrel{0}{0} \\
\vdots \\
0\end{array}$ & 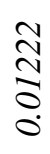 & $\underset{0}{\stackrel{\infty}{\triangleq}}$ & $\begin{array}{l}\widetilde{\widehat{\infty}} \\
\stackrel{8}{0} \\
0\end{array}$ & $\frac{n}{2}$ \\
\hline
\end{tabular}

Table 3. Upper covariance matrix

\begin{tabular}{|c|c|c|c|c|c|c|c|c|c|c|}
\hline ర్ర & $\frac{\sqrt{x}}{\sqrt{\alpha}}$ & 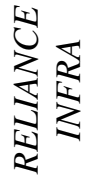 & $\Xi$ & $\underset{z}{\Sigma}$ & $\frac{\underset{\pi}{\vdots}}{\frac{\pi}{\Delta}}$ & ळొ & $\underset{2}{2}$ & $\underset{\mathbb{E}}{\mathbb{E}}$ & ¿ & 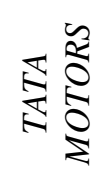 \\
\hline 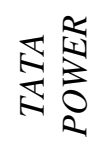 & 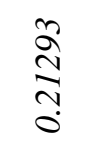 & 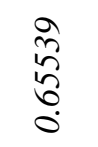 & 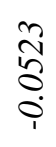 & 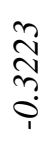 & 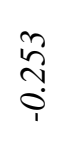 & $\frac{\stackrel{2}{ \pm}}{\frac{1}{0}}$ & $\frac{7}{2}$ & 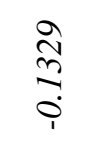 & $\frac{\pi}{3}$ & 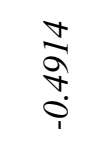 \\
\hline 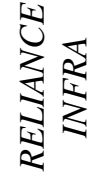 & $\begin{array}{l}0 \\
\hat{n} \\
\hat{2} \\
\vdots \\
0\end{array}$ & 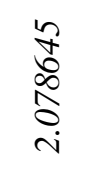 & $\frac{\hat{3}}{8}$ & $\begin{array}{l}0 \\
\infty 0 \\
\infty \\
\infty \\
\dot{0}\end{array}$ & 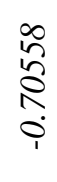 & 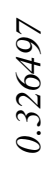 & $\begin{array}{l}0 \\
5 \\
0 \\
? \\
?\end{array}$ & $\begin{array}{l}n \\
n \\
m \\
n \\
0 \\
0\end{array}$ & $\begin{array}{l}\infty \\
\tilde{\infty} \\
0 \\
0 \\
\dot{0}\end{array}$ & 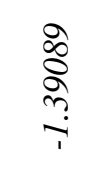 \\
\hline$\Xi$ & 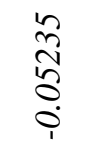 & $\begin{array}{l}\hat{3} \\
\frac{8}{8} \\
0 \\
1\end{array}$ & $\frac{\sqrt{2}}{\hat{2}}$ & $\begin{array}{l}\infty \\
\tilde{N} \\
\tilde{n} \\
\frac{7}{7} \\
0\end{array}$ & $\begin{array}{l}\overparen{2} \\
8 \\
0 \\
0\end{array}$ & 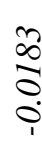 & $\begin{array}{l}\hat{0} \\
\infty \\
\infty \\
\stackrel{0}{0}\end{array}$ & $\begin{array}{l}\stackrel{\infty}{N} \\
\hat{N} \\
\infty \\
0 \\
0\end{array}$ & 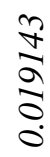 & 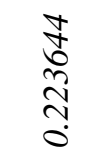 \\
\hline$\underset{z}{z}$ & 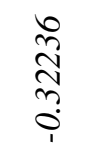 & $\begin{array}{l}0 \\
\infty \\
\infty \\
\infty \\
0 \\
1\end{array}$ & \begin{tabular}{l}
$\infty$ \\
\multirow{2}{n}{} \\
$\frac{2}{2}$ \\
0
\end{tabular} & 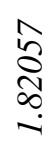 & \begin{tabular}{l}
$\infty$ \\
$\infty$ \\
$\infty$ \\
\multirow{1}{*}{} \\
$\infty$ \\
0
\end{tabular} & 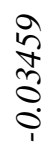 & 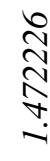 & 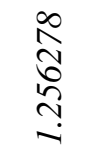 & 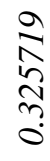 & 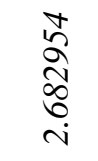 \\
\hline 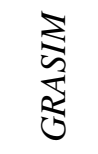 & $\begin{array}{l}\stackrel{+}{n} \\
\stackrel{n}{1} \\
\stackrel{1}{1}\end{array}$ & $\begin{array}{l}\infty \\
2 \\
2 \\
2 \\
0 \\
i\end{array}$ & 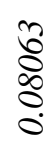 & \begin{tabular}{l}
$\infty$ \\
$\infty$ \\
$\infty$ \\
\multirow{+}{*}{} \\
$\infty$ \\
0
\end{tabular} & 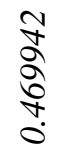 & 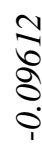 & $\begin{array}{l}2 \\
2 \\
2 \\
2 \\
\vdots \\
0\end{array}$ & $\begin{array}{l}\frac{n}{6} \\
\frac{6}{6} \\
\frac{7}{0}\end{array}$ & $\frac{n}{2}$ & $\frac{7}{2}$ \\
\hline
\end{tabular}




\begin{tabular}{|c|c|c|c|c|c|c|c|c|c|c|}
\hline ळ্ & $\frac{3}{\frac{2}{0}}$ & 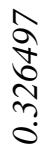 & $\frac{\infty}{\infty}$ & \begin{tabular}{l}
0 \\
\multirow{2}{*}{} \\
2 \\
0 \\
0
\end{tabular} & $\begin{array}{l}\text { ত̃ } \\
8 \\
0 \\
0 \\
0\end{array}$ & $\frac{\hat{\delta}}{\hat{\sigma}}$ & 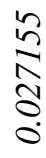 & 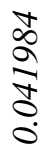 & $\begin{array}{l}\hat{n} \\
\hat{n} \\
0 \\
0 \\
0\end{array}$ & 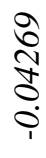 \\
\hline $\begin{array}{l}\frac{0}{2} \\
\vdots \\
\vdots\end{array}$ & 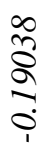 & $\begin{array}{l}\frac{9}{n} \\
2 \\
? \\
0 \\
1\end{array}$ & $\begin{array}{l}\hat{\infty} \\
\infty \\
\infty \\
0 \\
0\end{array}$ & 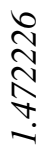 & $\begin{array}{l}2 \\
\infty \\
2 \\
\infty \\
0 \\
\vdots \\
0\end{array}$ & 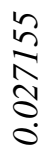 & $\begin{array}{l}\infty \\
0 \\
0 \\
\\
\\
-1\end{array}$ & 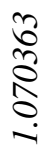 & 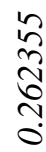 & $\begin{array}{l}\text { aे } \\
\text { ลे } \\
\text { ㅇ }\end{array}$ \\
\hline$\underset{\mathbb{W}}{\mathbb{W}}$ & 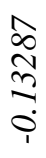 & $\begin{array}{l}n \\
n \\
n \\
n \\
0\end{array}$ & \begin{tabular}{l}
$\infty$ \\
\multirow{N}{N}{} \\
$\infty$ \\
0 \\
0
\end{tabular} & \begin{tabular}{l}
$\infty$ \\
\multirow{2}{0}{} \\
$\stackrel{n}{2}$
\end{tabular} & $\frac{\frac{n}{\sigma}}{\frac{n}{\sigma}}$ & 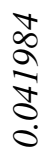 & 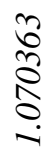 & 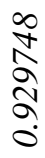 & 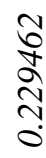 & $\begin{array}{l}\frac{0}{0} \\
\frac{0}{\infty} \\
-\end{array}$ \\
\hline$\underset{\vdots}{\vdots}$ & $\begin{array}{l}\frac{N}{n} \\
0 \\
0 \\
0\end{array}$ & $\begin{array}{l}\infty \\
\infty \\
\vdots \\
0\end{array}$ & $\stackrel{\overrightarrow{0}}{0}$ & กิ & $\frac{\nexists}{ \pm}$ & 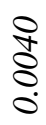 & 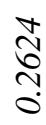 & 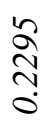 & $\underset{\sigma}{\stackrel{\nabla}{0}}$ & $\frac{n}{n}$ \\
\hline 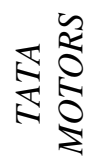 & $\begin{array}{l}\frac{\nabla}{a} \\
\dot{\sigma} \\
\dot{0}\end{array}$ & 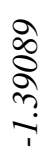 & 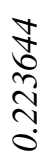 & 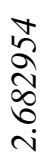 & $\begin{array}{l}\frac{7}{2} \\
\stackrel{5}{2} \\
\frac{1}{-}\end{array}$ & 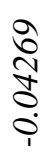 & $\begin{array}{l}\hat{\sigma} \\
\hat{\sigma} \\
\frac{\hat{\sigma}}{2}\end{array}$ & $\begin{array}{l}\frac{0}{3} \\
\frac{0}{\infty} \\
-1\end{array}$ & 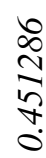 & 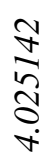 \\
\hline
\end{tabular}

Let $k_{i}=0.001, M=0.8, m=0.005, k=8, x_{i}^{0}=0, \forall i=1,2,3$,....... , 10.

Also let $\alpha=-0.8 ; \beta=0.9 ; \gamma=0.5 ; \lambda_{1}=0.4 ; \lambda_{2}=0.5 ; \lambda_{3}=0.3$.

Using these data, in this scenario let us solve the three portfolio optimization models $\langle 2\rangle,\langle 3\rangle,\langle 4\rangle$. The solution is done by MATLAB and result obtained after 50 crossover and mutations in each model is shown in Table 4.

Table 4. Solutions \& Constraints of models $\langle 2\rangle,\langle 3\rangle,\langle 4\rangle$

\begin{tabular}{|c|c|c|c|}
\hline Models & $\langle 2\rangle$ & $\langle 3\rangle$ & $\langle 4\rangle$ \\
\hline Return & {$[-0.3820,1.1265]$} & {$[-0.3883,1.0744]$} & {$[-0.3749,1.1028]$} \\
\hline Risk & {$[0.0524,0.3078]$} & {$[0.0379,0.3953]$} & {$[0.0416,0.2031]$} \\
\hline Dividend & {$[0.8214,1.9853]$} & {$[1.0880,2.1498]$} & {$[1.1245,2.1178]$} \\
\hline \multicolumn{3}{|c|}{ Portfolio } \\
\hline TATA POWER & 0.1259 & 0 & 0.1273 \\
\hline RELIANCE INFRA & 0.1258 & 0.1129 & 0.1248 \\
\hline ITC & 0 & 0.1298 & 0.1181 \\
\hline M\&M & 0 & 0.1418 & 0 \\
\hline GRASIM & 0.1236 & 0.1129 & 0.1278 \\
\hline SBI & 0.1223 & 0.1259 & 0.1245 \\
\hline WIPRO & 0.1263 & 0 & 0 \\
\hline TATA STEEL & 0.1272 & 0.1142 & 0.1276 \\
\hline ONGC & 0.1281 & 0.1259 & 0.1173 \\
\hline TATA MOTORS & 0.1208 & 0.1366 & \\
\hline
\end{tabular}

In figure 1 , the different portfolios for models $2-4$ are shown in the form of bar diagrams. 


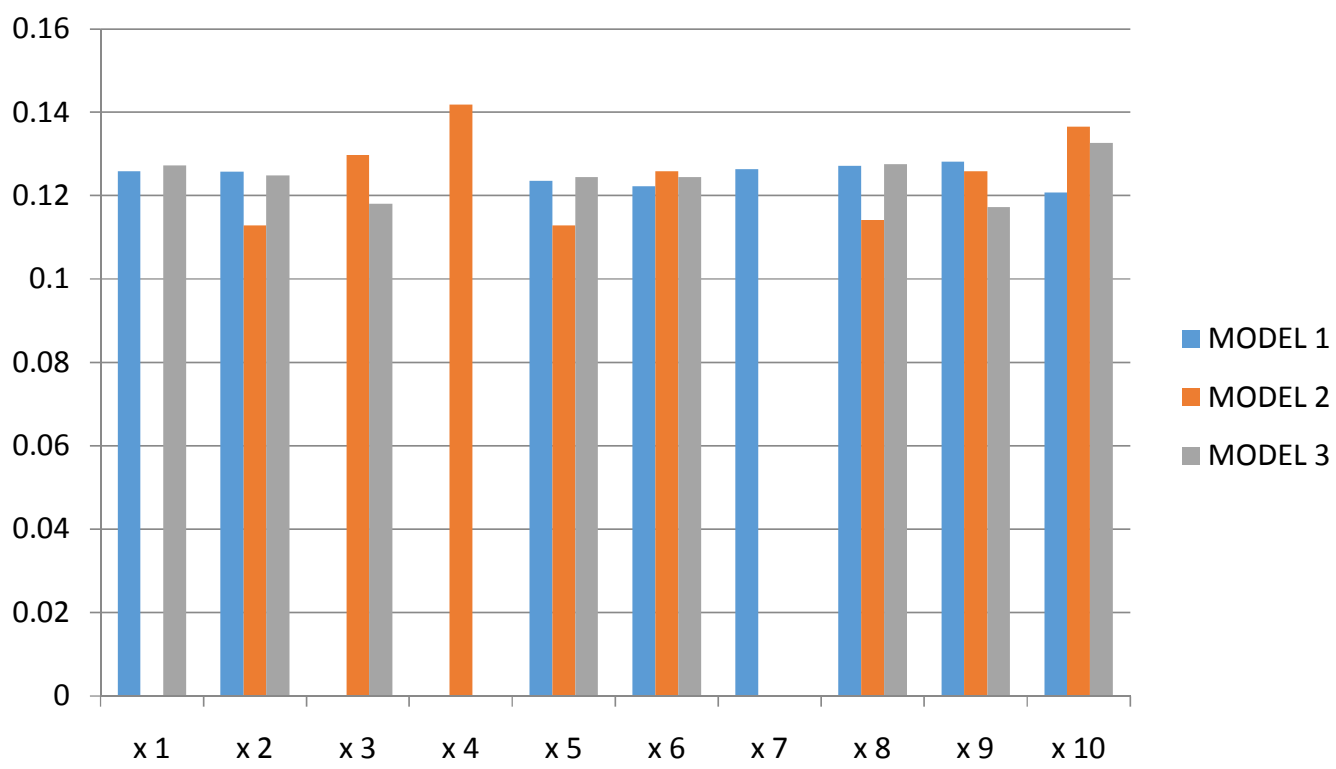

Figure 1. Allocation of capital for the three models

It is clear from the results shown in Table 4 for models 2-4 that in model $\langle 2\rangle$ the investor used the constraints pessimistically and optimistically in model $\langle 3\rangle$, while in case of model $\langle 4\rangle$, he was neither too optimistic nor too pessimistic, but a mixed one. This is prominent from the results of returns, risks and dividends obtained in each case:

$$
\begin{array}{ll}
\text { RETURN: } & {[-0.3749,1.1028] \subset[-0.3883,1.1265],} \\
\text { RISK: } & {[0.0416,0.2031] \subset[0.0379,0.3953],} \\
\text { DIVIDEND: } & {[1.1245,2.1178] \subset[0.8214,2.1498] .}
\end{array}
$$

From Figure 1, it is also evident that the investor is always allowed to handle with only 8 assets, and also each allocation is inside the desired margins.

\section{CONCLUSION}

This article has introduced a new framework for fuzzy portfolio selection using interval valued fuzzy numbers. A new objective function has been defined as the ratio of the entropy of the allocated proportions of investor's wealth to the total transaction costs. In addition to the objective function, eight different constraints including constraints on return, risk and dividends have been introduced in the models. Three different models representing pessimistic, optimistic and balanced preference of the investors have been proposed. The return, covariance and dividends of the stocks are represented by interval numbers. The models are tested on stock data from BSE. The solution is done by the software MATLAB.

In future, the methodology presented here can be extended to the portfolio selection problems in fuzzy, hybrid and general uncertain environments. In addition, genetic algorithm, hybrid intelligent algorithm, tabu search, simulated annealing, ant-colony optimization and particle swam optimization may be employed to solve the non-linear programming problem. 


\section{REFERENCES}

[1] L. Bachelier, Theorie de la Speculation: Thesis: Annales Scientifiques de l'École Normale Superieure (1900); I I I 17; 21-86.

[2] H. Markowitz, Portfolio selection, Journal of Finance 7 (1952) 77-91.

[3] F.D. Arditti, Risk and the required return on equity, Journal of Finance 22 (1967) 19-36.

[4] P. Samuelson, The fundamental approximation theorem of portfolio analysis in terms of means, variances an higher moments, Review of Economic Studies 25 (1958) 65-86.

[5] A. Kraus, R. Litzenberger, Skewness preference and the valuation of risky assets, Journal of Finance 21 (1976) 1085-1094.

[6] H. Konno, H. Shirakawa, H. Yamazaki, A mean-absolute deviation-skewness portfolio optimization model, Annals of Operations Research 45 (1993) 205-220.

[7] H. Konno, K. Suzuki, A mean-variance-skewness optimization model, Journal of the Operations Research Society of Japan 38 (1995) 137-187.

[8] S.C. Liu, S.Y. Wang, W.H. Qiu, A mean-variance-skewness model for portfolio selection with transaction costs, International Journal of Systems Science 34 (2003) 255-262.

[9] A.J. Prakash, C. Chang, T.E. Pactwa, Selecting a portfolio with skewness: Recent evidence from US, European, and Latin American equity markets, Journal of Banking and Finance 27 (2003) 1375-1390.

[10] T. Lai, Portfolio selection with skewness: a multiple-objective approach, Review of the Quantitative Finance and Accounting 1 (1991) 293-305.

[11] P. Chunhachinda, K. Dandapani, S. Hamid, A.J. Prakash, Portfolio selection and skewness: evidence from international stock markets, Journal of Banking and Finance 21 (1997) 143-167.

[12] W. Briec, K. Kerstens, O. Jokung, Mean-variance-skewness portfolio performance gauging: a general shortage function and dual approach, Management Science 53 (2007) 135-149.

[13] L. Yu, S.Y. Wang, K. Lai, Neural network based mean-variance-skewness model for portfolio selection, Computers and Operations Research 35 (2008) 34-46.

[14] L. A. Zadeh ,1965, Fuzzy Sets, Information and Control, 8, 338-353.

[15] S. Ramaswamy, Portfolio selection using fuzzy decision theory, Working paper of Bank for International Settlements, 59, 1998.

[16] M.A. Parra, A.B. Terol, M.V.R. Uría, A fuzzy goal programming approach to portfolio selection, European Journal of Operational Research 133 (2001) 287-297.

[17] W. Zhang, Z. Nie, On admissible efficient portfolio selection problem, Applied Mathematics and Computation 159 (2004) 357-371.

[18] A. Bilbao-Terol, B. Perez-Gladish, M. Arenas-Parra, M.R. Urfa, Fuzzy compromise programming for portfolio selection, Applied Mathematics and Computation 173 (2006) 251-264.

[19] P. Gupta, M.K. Mehlawat, A. Saxena, Asset portfolio optimization using fuzzy mathematical programming, Information Sciences 178 (2008) 1734-1755.

[20] X. Huang, Mean-semivariance models for fuzzy portfolio selection, Journal of Computational and Applied Mathematics 217 (2008) 1-8.

[21] X. Huang, Risk curve and fuzzy portfolio selection, Computers and Mathematics with Applications 55 (2008) 1102-1112.

[22] C.C. Lin, Y.T. Liu, Genetic algorithms for portfolio selection problems with minimum transaction lots, European Journal of Operational Research 185 (2008) 393-404.

[23] R. Bhattacharyya, M.B. Kar, S. Kar, D. Dutta Majumder, in: S. Chaudhury, et al. (Eds.), Mean-EntropySkewness Fuzzy Portfolio Selection by Credibility Theory Approach, in: LNCS 5909, PReMI 2009, 2009, pp. 603-608.

[24] R. Bhattacharyya, S. Kar, Possibilistic mean-variance- skewness portfolio selection models, International Journal of Operations Research, 8(3), 44- 56, 2011.

[25] R. Bhattacharyya, S. Kar, Multi-objective fuzzy optimization for portfolio selection: an embedding theorem approach, Turkish Journal of Fuzzy Systems, 2(1), 14 - 35, 2011.

[26] X. Li, Z. Qin, S. Kar, Mean-variance-skewness model for portfolio selection with fuzzy returns, European Journal of Operational Research 202 (2010) 239-247.

[27] I. Grattan-Guinness, Fuzzy membership mapped onto interval and many valued quantities, Mathematical Logic Quarterly 22 (1976) 149-160.

[28] K.U. Jahn, Interval-wertige mengen, Mathematische Nachrichten 68 (1975) 115-132.

[29] R. Sambuc, Functions $\Phi$-floues, Applications á l'aide au diagonostic en pathologie thyroidienne, Ph.D. Thesis, University of Marseille, 1975.

[30] L.A. Zadeh, The concept of a linguistic variable and its application to approximate reasoning-I, Information Sciences 8 (1975) 199-249. 
[31] K.K. Lai, S.Y. Wang, J.P. Xu, S.S. Zhu, Y. Fang, A class of linear interval programming problems and its application to portfolio selection, IEEE Transactions on Fuzzy Systems 10 (2002) 698-704.

[32] M. Ida, Portfolio selection problem with interval coefficients, Applied Mathematics Letters 16 (2003) 709713.

[33] M. Ida, Solutions for the portfolio selection problem with interval and fuzzy coefficients, Reliable Computing 10 (2004) 389-400.

[34] S. Giove, S. Funari, C. Nardelli, An interval portfolio selection problems based on regret function, European Journal of Operational Research 170 (2006) 253-264.

[35] Y. Fang, K.K. Lai, S.Y. Wang, Portfolio rebalancing model with transaction costs based on fuzzy decision theory, European Journal of Operational Research 175 (2006) 879-893.

[36] M. Ehrgott, K. Klamroth, C. Schwehm, An MCDM approach to portfolio optimization, European Journal of Operational Research 155 (2004) 752-770.

[37] R. Bhattacharyya, et al., Fuzzy mean-variance-skewness portfolio selection models by interval analysis, Computers and Mathematics with Applications, 61 (2011), 126 - 137.

[38] Kapur J, and Kesavan H,Entropy Optimization Principles with Applications, Academic Press, New York, 1992.

[39] Jaynes, E.T. (1957), "Information theory and statistical mechanics", The Physical Review, Volume 106, No. 4, 620-630, May 15, 1957.

[40] Jaynes, E.T. (1957), "Information theory and statistical mechanics II", The Physical Review, Volume 108, No. 2, 171-190, October 15, 1957.

[41] Fang S, Rajasekera J, and Tsao H, Entropy Optimization and Mathematical Programming, Kluwer Academic, Boston, 1997.

[42] Qin Z, Li X, and Ji X, Portfolio selection based on Fuzzy cross-entropy, JCAM, Vol. 228, 139-149, 2009.

[43] Li X and Liu B, Maximum Entropy Principle for fuzzy variables, International Journal of Uncertainity, Fuzziness \& Knowledge-Based Systems, Vol. 15, Supp. 2, 43-52, 2007.

[44] Liu B, A survey of entropy of fuzzy variables, Journal of uncertain systems, Vol. 1, No. 1, 4-13, 2007.

[45] L.A. Zadeh, Fuzzy sets as a basis for a theory of possibility, Fuzzy Sets and Systems 1 (1978) 3-28.

[46] H. Rommerlfanger, R. Hanscheck, J. Wolf, Linear programming with fuzzy objectives, Fuzzy Sets and Systems 29 (1989) 31-48.

[47] H. Ishihuchi, M. Tanaka, Multiobjective programming in optimization of the interval objective function, European Journal of Operational Research 48 (1990) 219-225.

[48] J. H. Holland, Adaptation in Natural and Artificial Systems, University of Michigan Press, Ann Arbor, 1975.

[49] D. Bhandari, C.A. Murthy, S.K. Pal, Genetic algorithm with elitist model and its convergence, International Journal of Pattern Recognition and Artificial Intelligence 10 (6) (1996) 731-747.

[50] X. Huang, Fuzzy chance-constrained portfolio selection, Applied Mathematics and Computation 177 (2006) 500-507.

\section{AUTHORS}

Mr. Mainak Dey is presently working as an Assistant Professor in the Department of Mathematics of Camellia Institute of Engineering, Madhyamgram, West Bengal, India. He received his MSc. degree from Indian Institute of Technology, Roorkee, India and BSc. from Jadavpur U niversity, Kolkata. Currently he is pursuing research work leading to $\mathrm{PhD}$ degree under the necessary guidance of Dr. Rupak Bhattacharyya. His research interests include Fuzzy Mathematics, Portfolio Management, Optimization and Operation Research.

Dr. Rupak Bhattacharyya is presently working as an Associate Professor (Mathematics) and HOD in the Department of Applied Science \& Humanities of Global Institute of Management \& Technology, Krishnagar, West Bengal, India. He received his $\mathrm{PhD}$ degree from National Institute of Technology, Durgapur. The Operational Research Society of Indi a confers the Professor M N Gopalan Award on Dr. Bhattacharyya for the best Doctoral Thesis in Operational Research of 2011. He has more than eight years of teaching and research experience. He has more than 20 International publications. His research interest includes Soft Computing, Financial Mathematics and Optimization.

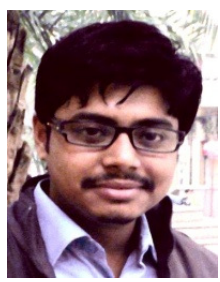
Details on Dr. Bhattacharyya can be viewed from: https://sites.google.com/site/rupakmath

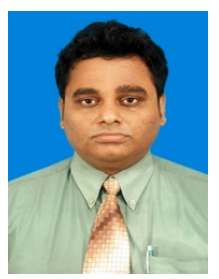

